\title{
Prof. Erino Angelo Rendina: keep passionate and dream big
}

Submitted Nov 22, 2018. Accepted for publication Nov 29, 2018.

doi: $10.21037 /$ jtd.2018.12.19

View this article at: http://dx.doi.org/10.21037/jtd.2018.12.19

\section{Editor's note}

The AATS Focus on Thoracic Surgery: Lung and Esophageal Cancer was successfully held in Guangzhou, China, from 3rd to 4th of November in 2018. It was a fantastic academic journey, gathering many renowned surgeons and scholars from all around world to exchange new ideas and experiences.

During the meeting, Prof. Erino Angelo Rendina from University La Sapienza (Italy), made two wonderful academic speeches titled, "Salvage Resection of advanced Mediastinal tumors" and "Surgical Techniques of Bronchial and Pulmonary Artery Reconstruction" (Figure 1). Seizing this opportunity, we are honored to invite Prof. Rendina for an interview.

At the beginning, Prof. Rendina said he was impressed by the excellent surgical techniques demonstrated during the Chinese colleague's presentations. Later, we met with him this year to discuss his perspectives on thoracic surgery and his views on the field as a profession.

Professor Rendina said that surgical treatment is rewarding for both the patient and the surgeon, and that thymic tumors respond very well to a resection treatment procedure. Therefore, even when the tumor is very aggressive, and even if chemotherapy before surgery is not so successful, there is a good chance that there will be success after a surgical resection.

As for the biggest challenge in the salvage resection of advanced mediastinal tumors, Prof. Rendina told us that one of the biggest difficulties are the infiltration of the veins in the mediastinum, such as the superior vena cava and the innominate veins. Although the infiltration of the veins occurs quite frequently, it can be manageable. Another challenge is the infiltration of an artery. In that case, a cardiopulmonary bypass $(\mathrm{CPB})$ procedure may be needed; however, once $\mathrm{CPB}$ is used, the patient's entire cardiovascular system becomes compromised, which make the operation a big risk.

Prof. Rendina and his team have made great efforts in bronchial and pulmonary artery reconstruction, and have come up with many novel surgical treatments, such as the Y-sleeve resection. In regard to being asked about this procedure's advantages and disadvantages, Prof. Rendina acknowledged that although it can resect tumors which look

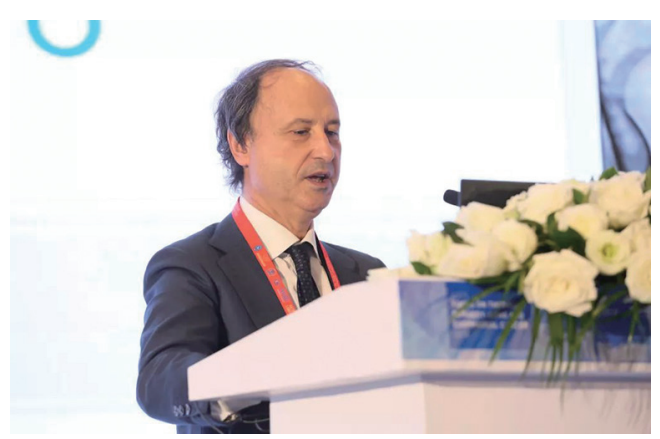

Figure 1 Prof. Erino Angelo Rendina is delivering a speech at AATS Focus 2018.

unresectable at the beginning. The success of the procedure heavily lies in the preoperative evaluation of the patients. It is difficult to determine whether or not mediastinal tumors can be operated on and resected only on the basis of computer tomography scan result. Sometimes surgeons have to go to surgery and check directly, which will expose the patients to the risks burdened by an operation just to find out that the tumor cannot be resected. However, if surgeons study the patients well, the number of exposing to this kind of re-procedure is very low.

After talking seriously about academics, Prof. Rendina was delighted to share with us his philosophy of life and the message to the young medical students.

To our surprise, Prof. Rendina said he is not a workaholic, but believes in the saying that family comes first. However, he is very clear about the responsibility he shoulders. He explained that when he was younger, what had really captured his interest about learning was the techniques and breakthroughs in medicine. But when he became older, it gradually became clearer to him, his commitment to his patients and to the younger generations. As a surgeon, the patients are the most important actor in his professional life. Pushing the boundary is meaningless, unless it can benefits patients, rather than just satisfying one's ego.

As a university professor, Prof. Rendina said being a doctor is the most beautiful job in the world provided that is done with passion, not for making a career. To the young 


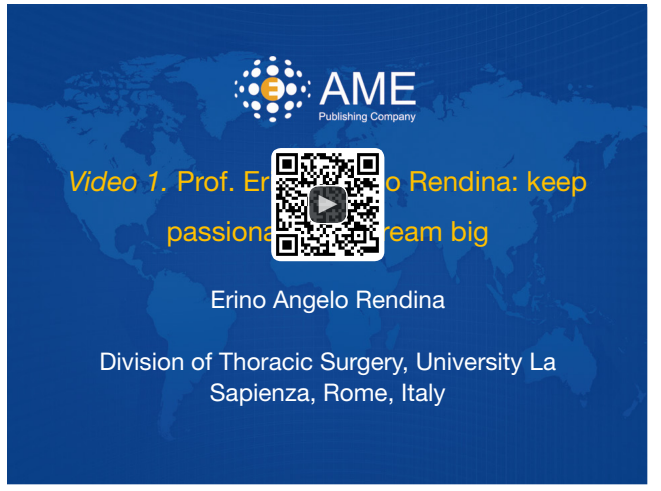

Figure 2 Prof. Erino Angelo Rendina: keep passionate and dream big (1).

Available online: http://www.asvide.com/article/view/29200

medical students who want to be successful in his filed, Prof. Rendina said, "What I advise to the young surgeons is to keep your dreams and dream big, and preserve your passion for medicine. If you are passionate with medicine, you will certainly be successful."

\section{Expert introduction}

Professor Rendina was born in Rome in 1958. He achieved a MD degree and Board Certification in Thoracic Surgery at Sapienza University of Rome with commendation. He also received his postgraduate training in the USA, Japan, France, Germany, and the UK.

He is a professor and Chief the Department of Thoracic Surgery in University La Sapienza Rome. He has been a visiting professor at many renowned universities, such as Harvard University, the Washington University. He was the former president of the European Association of CardioThoracic Surgery in 2008 and the Associate Editor of the European Journal of Cardio-thoracic Surgery from 2003 to 2014. He also was the first Italian thoracic surgeon member of the American Association for Thoracic Surgery [2000] since its foundation in 1917.

$\mathrm{He}$ is an active member in several professional societies like the Society of Thoracic Surgery, European Association of Cardio-Thoracic Surgery and European Society of Thoracic Surgery. He is the Author of over 320 papers in peer reviewed journals with an impact factor of $>800$; h-index 36 .

He performed the first lung transplant in Italy at the age of 32, on the date of January 11th, 1991. Since then, he performed more than 70 single and bilateral transplantation procedures. He is the chairman for the Sant'Andrea
Hospital Thoracic Surgery Division since Jan 2003. There, over 1,200 major procedures are performed yearly. Among these, reconstruction of the trachea, superior vena cava, carina, bronchi and pulmonary artery are performed.

\section{Interview questions (Figure 2)}

(I) Which part impressed you the most during the meeting?

(II) Would you like to talk about the wind of change in treating thymic tumors? What are the important principles and rules to be followed?

(III) What is the biggest challenge in the salvage resection of advanced mediastinal tumor? How do you manage it?

(IV) What are the advantages and limitations of the novel surgical technique (Y-sleeve resection) mentioned in your presentations?

(V) As a renowned surgeon in thoracic surgery, you are occupied with clinical researches, medical educations and plenty of meetings. How do you manage your work and life?

(VI) What motivates you to push your limit in your career?

(VII) What message do you want to send to the young medical students who want to be successful in your field?

\section{Acknowledgements}

None.

\section{Footnote}

Conflicts of Interest: The author has no conflicts of interest to declare.

\section{References}

1. Yuan A. Prof. Erino Angelo Rendina: keep passionate and dream big. Asvide 2018;5:938. Available online: http:// www.asvide.com/article/view/29200

(Science Editor: Amber Yuan, JTD, jtd@amepc.org) (English Language Editor: Jeremy Dean Chapnick, AME Publishing Company)

Cite this article as: Yuan A. Prof. Erino Angelo Rendina: keep passionate and dream big. J Thorac Dis 2018;10(12):E846-E847. doi: $10.21037 /$ jtd.2018.12.19 